\title{
Involving young people in drug and alcohol research
}

\author{
Louca-Mai Brady, Lorna Templeton, Paul Toner, Judith Watson, David Evans, \\ Barry Percy-Smith and Alex Copello
}

The authors affiliations can be found at the end of this article.

Received 29 August 2017 Revised 8 December 2017 Accepted 9 January 2018

(C) Louca-Mai Brady, Lorna Templeton, Paul Toner, Judith Watson, David Evans, Barry Percy-Smith and Alex Copello. Published by Emerald Publishing Limited. This article is published under the Creative Commons Attribution (CC BY 4.0) licence. Anyone may reproduce, distribute, translate and create derivative works of this article (for both commercial \& non-commercial purposes), subject to full attribution to the original publication and authors. The full terms of this licence may be seen at http://creativecommons.org/ licences/by/4.0/legalcode

This Y-SBNT study was funded by the NIHR Health Technology

Assessment Programme (project number 11/60/01)

The views and opinions expressed herein are those of the authors and do not necessarily reflect those of the Health Technology

Assessment Programme, NIHR NHS or the Department of Health. The study was coordinated by the University of Birmingham and sponsored by Birmingham and Solihull Mental Health Foundation Trust. The associated PhD by Louca-Mai Brady was supported by a bursary from the University of the West of England, and supervised by Barry Percy-Smith and David Evans (co-authors on this paper). The authors would like to thank to all the young people who have been involved in the project, all the services and staff who supported their involvement, and to the members of study team not involved in the development of this paper including Sangeeta Ambegaokar, Donna Back, Ed Day, Charlie Lloyd, Eilish Gilvarry and Paul McArdle.

\begin{abstract}
Purpose - Young people's involvement should lead to research, and ultimately services, that better reflect young people's priorities and concerns. Young people with a history of treatment for alcohol and/or drug problems were actively involved in the youth social behaviour and network therapy study. The purpose of this paper is to explore the impact of that involvement on the study and what was learnt about involving young people in drug and alcohol research.
\end{abstract}

Design/methodology/approach - The initial plan was to form a young people's advisory group (YPAG), but when this proved problematic the study explored alternative approaches in collaboration with researchers and young people. Input from 17 young people informed all key elements of the study.

Findings - Involvement of young people needs to be dynamic and flexible, with sensitivity to their personal experiences. Engagement with services was crucial both in recruiting young people and supporting their ongoing engagement. This research identified a need to critically reflect on the extent to which rhetorics of participation and involvement give rise to effective and meaningful involvement for young service users. It also highlights the need for researchers to be more flexible in response to young people's personal circumstances, particularly when those young people are "less frequently heard".

Research limitations/implications - This research highlights the need for researchers to be more flexible in response to young people's personal circumstances, particularly when those young people are "less frequently heard". It highlights the danger of young people in drug and alcohol research being unintentionally disaffected from involvement through conventional approaches and instead suggests ways in which young people could be involved in influencing if and how they participate in research.

Practical implications - There is an apparent contradiction between dominant discourses and cultures of health services research (including patient and public involvement) that often do not sit easily with ideas of co-production and young people-centred involvement. This paper provides an alternative approach to involvement of young people that can help to enable more meaningful and effective involvement.

Originality/value - The flexible and young people-centred model for involvement which emerged from this work provides a template for a different approach. This may be particularly useful for those who find current practice, such as YPAG, inaccessible.

Keywords Participation, Co-production, Young people, PPI, Public involvement, Children's rights

Paper type Research paper

\section{Introduction}

\section{Young people's involvement in the Y-SBNT study}

Family interventions appear to be an important element of young people's drug and alcohol treatment (Velleman et al., 2005), however, implementation of family approaches in UK services is low (Watson et al., 2017). The Youth Social Behaviour and Network Therapy (Y-SBNT) study (Watson et al., 2015) was a randomised controlled trial (RCT) which aimed to demonstrate the feasibility of recruiting young people to a specifically developed family- and wider social network-based intervention by adapting and then testing a version of adult SBNT (Copello et al., 2009). This involved adapting the original evidence-based family and social network intervention (SBNT) developed and tested with adult alcohol misusers to the youth context. Adaptation of the intervention included the involvement of young people with 
experience of drug and alcohol services, as discussed in this paper, as well as consultation with treatment professionals working with young people. A pragmatic, two-armed randomised controlled open feasibility trial followed, based in two UK-based treatment services. In all, 53 young people aged 12-18 years, newly referred and accepted for structured interventions for drug and/or alcohol problems, were recruited and randomised 1:1 to receive either the adapted Y-SBNT intervention or treatment as usual. This paper focusses on learning from one specific element of the study: the involvement of young people in the research process, and the findings of the wider feasibility trial are reported elsewhere (Watson et al., 2017). Overall, the aim was to maximise opportunities for young people's involvement in the adaptation of the intervention and trial to ensure that both addressed the issues faced by young people with alcohol and/or drug problems. The study was also a case study in doctoral research by one author (L-MB) on how young people's involvement can be embedded in health services and research[1] (Brady, 2017). This paper draws on this doctoral research and the study report (Watson et al., 2017), and is informed by the GRIPP2 guidance on reporting patient and public involvement in research (Staniszewska et al., 2017).

All publicly funded health research in the UK, including the study discussed in this paper, is now expected to have some element of public involvement (Evans et al., 2014). Involving those who are the focus of research has been found to have a positive impact on what is researched, how research is conducted and the impact of research findings on services and in the lives of those involved (Brett et al., 2014; Staley, 2009). The United Nations Convention on the Rights of the Child (UN, 1989) has established international recognition that all children have a right to the highest possible standards of both healthcare and involvement (Alderson, 2014) as well as a right to have a say in decisions that affect them. The understanding that children and young people should be involved in decisions which affect them has been increasingly reflected in UK law, guidance, regulation and policy in relation to health and social care (Department of Health, 2013; Franklin and Sloper, 2005). But there has been less attention paid to the experiences and impact of involving children and young people than the involvement of adults (Bird et al., 2013). Involvement should lead to research, and ultimately services, that better reflect young people's priorities and concerns (Brady et al., 2012; Fleming and Boeck, 2012). This is especially important for young people deemed to be more "vulnerable", whose voices are often absent from the literature (Richards et al., 2015). For example, users of mental health services (Mawn et al., 2015), those who are looked after (in the care system) (Powell and Smith, 2009) and young people with alcohol and/or drug problems (Brady, 2017). The work discussed in this paper focussed on involvement as commonly defined in health and social care research as "research [...] carried out ' with' or 'by' members of the public rather than 'to', 'about' or 'for' them" (INVOLVE, 2016). But the terminology of involvement, participation and engagement can be contradictory and opaque, compounded by the increasing popularity of co-production, which is becoming an increasingly popular term in policymaking, governance, and research (Filipe et al., 2017). However, work by National Institute for Health Research (NIHR) INVOLVE found that:

[...] [co-production]'s application in health and social care research varies, revealing a lack of consensus around the concept. Some argue that co-production in research is just "really good PPI [patient and public involvement]". For others it is very different; a much more deliberative process which requires public members and "professionals" to be involved on an equal footing throughout every stage of the design and delivery of research (www.invo.org.uk/current-work/co-production/).

Furthermore, there are tensions between the participatory intent of co-production and the "expert"-driven notion of RCTs. The paper explores the lessons emerging from the involvement of a group of young people who are "less frequently heard" and was conducted as part of a $\mathrm{PhD}$ that focussed on understanding what it means to embed young people's participation in health services and research. The main aim was to explore whether and how young drug and alcohol service users could be meaningfully and effectively involved in an RCT.

\section{Methods}

The initial plan for young people's involvement in the Y-SBNT study was to form a young people's advisory group (YPAG) of 10-12 young people with previous experience of drug and alcohol treatment services. The YPAG is a common model for young people's involvement in health and 
social care research (http://generationr.org.uk/; http://decipher.uk.net/public-involvement/ young-people/), and we also drew on published guidance (Kirby, 2004; INVOLVE, 2015; Shaw et al., 2011). The original aim was for the young advisors to work alongside the research team, supported by the study's public involvement leads, through a series of group meetings. But recruitment proved slower than anticipated, and initial meetings were poorly attended.

We therefore worked with young advisors to develop a more flexible model that focussed on what worked for the young people, recruiting through services known to the study team and in our localities. Involvement centred on consultations with young people at locations familiar to them, supplemented with e-mails, text messages, telephone conversations and postal correspondence. Young people were given the option of ongoing involvement as a young advisor, without obligation to do so. Regular newsletters, with contributions from young advisors where possible, were sent to all the involved young people, with the aim of keeping them informed even if they were unable to attend meetings or be involved in other ways.

\section{Source material}

A range of qualitative data was collected to inform our understanding of, and learning from, young people's involvement. Data collection included transcriptions of focus groups with the study's trial management group (TMG) and steering committee (TSC), phone and face-to-face meetings with the two young advisors who had long-term involvement in the study and conversations from young advisor meetings. The analysis also drew on TMG and TSC meeting notes, newsletters and other materials developed for and with young people, and notes from meetings with organisations supporting the engagement of young people in the study.

A thematic analysis approach was used to discover, interpret and report on themes and patterns of meaning within all of this qualitative material (Braun and Clarke, 2013). Informed by Eisenhardt's (1989) paper on building theory from case study research, this involved initial thematic maps structured around research questions, a review of the literature and initial reflections. Transcribed materials and other qualitative documents were then coded to test the "fit" of the data with the initial themes identified, refining the thematic maps and identifying broader patterns and themes in an iterative process (see Brady, 2017, ch.4). Ethical approval for the Y-SBNT study (including young people's involvement) was given by NRES Committee West Midlands - Coventry and Warwickshire, and for the doctoral research by the University of the West of England Research Ethics Committee. All contributors gave informed consent.

\section{Young people's contribution to the study}

Young people contributed to all three phases of the study (see Box 1). During phase one (intervention development) they contributed to the design of the intervention, ensuring it was acceptable and relevant to the Y-SBNT study's target groups. During phase two (the randomised controlled feasibility trial) and phase three (analysis and reporting of data from the feasibility trial) young people's involvement included input into the design of recruitment and training materials, data collection tools, data analysis and interpretation, reporting and dissemination. This included co-presenting at a conference (Brady et al., 2014) and co-authoring written outputs (Brady et al., 2015; Chapter 8, Watson et al., 2017).

\section{Box 1: Summary of young people's involvement in the study}

In total, 17 young people were involved as young advisors in some capacity. The young people came from five areas of England (the West Midlands, the North East and the West of England, London and Oxfordshire). The 17 young people included 12 females and five males ranging in age from 16 to 21 years, with an average age of 18 years. Ten young people were involved in the study once, five twice and two on five or more occasions. We met young people face-to-face on 20 occasions. Contact was also maintained by post, text message, e-mail or telephone call, depending on the preferences of the young people involved. 


\section{Findings}

\section{"Why we got involved": young advisor's perspectives}

In the spirit of involving young people in all aspects of the study, these findings start with the views of the two young advisors who had the most long-standing involvement in the project (20 and 23 months):

I think it's important to involve young people in the Y-SBNT project because it's actually about young people, and I think they should have an input into it and not just the adults. I think it's important to involve young people who have used drug and alcohol services as they can understand what it's like for others who are in the shoes that they've been in - no offence to people that have got degrees! We have sort of walked the walk, so we know that stuff that other young people using services have to go through on a daily basis.

I wanted to get involved with this project because I've always wanted to do something like this to show others that it is possible and there is light at the end of the tunnel - and that no matter what circumstances they're in they've always got a voice. I want to make things better, I actually don't care as much what I get out of it, I just don't want to see any other young person suffering the way I had to, or end up dead or in prison. If I can help develop something that prevents that then I will (Young advisor A).

I got involved in the project because I think that it's important that young people can get the help that they need in the most helpful and supportive way so it doesn't damage them. I think I've gained an insight into research with young people and the opinions of young people held by social agencies and professional networks. A project for young people should definitely consult young people and should be based around their views. Young people who have used drug and alcohol services will be able to reflect on their past use of services and give relevant feedback. Reading the chapter [on public involvement in the study report] and all the findings and the work you've done, and l've done, made me feel like my views are important. It's the first time a group of professionals have taken things I've said and made use of it, and benefited from it, in an academic project. I'm very much used to discussing my substance use history in a very negative light with no real benefit at the end, but this project has helped me realise that a negative experience has made me wiser (Young advisor B).

\section{The need for flexibility}

The young people's perspectives above highlight the benefits as well as the challenges of working with a group of young people who had complex lives and little or no experience of either involvement or research. This challenged our thinking about how young people were involved in the study. We found that facilitating the input from young people needed to be dynamic and flexible in relation to the rhythms, preferences and commitments in their own lives:

Perhaps that sort of [YPAG] group structure isn't going to work with these sorts of young people in a project like this. And I think it is good to have a group and people fire off each other [...] but I still think the individual-level stuff that we've had has been really good and that's worked well and in a more natural way and perhaps this group need that level of support [...] because they're pretty chaotic, [with] multiple problems (Research team member, TMG focus group).

My mental health has sometimes made it difficult for me to be involved [in the project] [...]. But I like how, if I can't come to a meeting, we can have a phone call instead or you're just a text [message] away, or we can do stuff by post. I've not always been well enough to come and see people face-to-face but that doesn't mean I couldn't be involved in things, whereas some organisations I've been involved with would have said 'you're ill or you couldn't come to a meeting so you can't be involved (Young advisor A).

What I've liked is the flexibility. I've never had to make my own way to one of these meetings [...] of course it is a research project so there is a certain amount of formality about it but [individual involvement] keeps it relevant and convenient for to the young person which is always good (Young advisor B).

However, the individual model of one-to-one work with one of the public involvement leads, supported by group work where possible, could lead to some young people being more isolated. One young person, who was mainly involved in this way because of availability and geography, said that, although she appreciated the flexibility and convenience of meeting at a time and place that suited her, she would have liked to meet other young advisors and more members of the research team. 
Whilst adults think it is useful for young people to participate, and indeed young people may perceive benefits to involvement, we found that the young advisors often had other priorities:

Young people in my age group are in a very transitional stage of life, it's hard to commit long term.

Some young people relapse, or simply don't like discussing their problem in depth (Young advisor B).

Keeping in touch was also sometimes problematic; many of the young people we worked with were in hostel or other temporary accommodation, moving several times during the course of the project, as well as changing mobile phones. Lack of internet access and other personal reasons also meant that many did not have regular access to a computer or the internet or chose not to use e-mail or social media. We addressed this by working on young people-centred ways, discussing with the young people how best to keep in touch.

\section{The need for sensitivity}

Involvement in the study required young advisors to draw on their own experiences as users of drug and alcohol services, as well as considering the ways in which their family and wider networks had helped or hindered their recovery. Young advisors pointed out that, in this context, individual involvement may sometimes be more appropriate than group meetings:

This project talks about really personal stuff and the only way I can talk openly and honestly is because I've had a chance to get to know you [public involvement lead] face-to-face and because I trust you. It wouldn't work otherwise (Young advisor A).

The skills and experience young people can gain is often cited as a benefit of involvement, but we found that in a study such as this crediting young people's involvement can be problematic:

As much as I would love to put on my CV that I've been involved [...] people might wonder why l've been an advisor to a drug project [...] it just raises a few question marks [...] I do always have that worry that they're going to think 'Oh she was a druggie' and yes it's the truth but I don't want every employer knowing that stuff (Young advisor B).

Several of the young people involved in the study were living in care or in crisis, or had co-existing mental health problems. Young people with complex needs may feel powerless about decisions affecting their life and found it difficult to actively say "no" to involvement, instead opting out by remaining silent or not responding to contact (Waldman, 2005). This was certainly our experience as all the young people who opted out of further involvement did so by not responding to contact rather than actively opting out. However, both of the two long-standing young advisors had periods when they were unable to be involved in the project but subsequently re-engaged with it when their circumstances changed. We found that it was important to maintain a balance between keeping in contact and leaving the door open for future re-engagement, and not making young people feel "hassled".

\section{The role of services}

Adults, either parents and carers or professionals, often act as "gatekeepers" to young people and can either facilitate or constrain their involvement (Cree et al. , 2002; Hood et al., 1996). It was sometimes difficult to engage the interest of services in the potential opportunities that involvement could provide for young people:

Some professionals don't see the value of these projects and don't commit to recruiting young people.

Without this you just can't engage young people and do projects like this (Young advisor B).

Some services were reluctant to pass information on to young people because they were concerned about young people being too vulnerable or, conversely, because they thought that young people might not be "academic" or reliable enough. But when we were able to successfully involve young people in the project, the role of services was crucial both in recruitment and in supporting their ongoing engagement. The young people who become engaged almost all did so because someone in a service understood what we were doing and actively promoted the opportunity to young people and supported their engagement. 


\section{Developing a different approach to involving young people}

Despite the challenges we faced in identifying and recruiting young people with experience of alcohol and/or drug problems for ongoing involvement in the study, young people were actively involved through all stages of the research. Being a doctoral case study also created the opportunity for additional reflection and learning. Towards the end of the study we worked with the young advisors to reflect on what we had learnt and how we might best involve young people in future studies. Both researchers and young advisors felt that, ultimately, some form of ongoing group was the best way to involve young people; but one that was more flexible and young people-centred than a fixed-location YPAG with a largely static membership. Instead what emerged was the need for a more fluid "community of practice" (Wenger, 1998) in which young people can gradually develop capacity for engagement on their own terms, in what Lave and Wenger (1998) refer to as "legitimate peripheral participation".

Box 2 summarises the model which we developed in collaboration with the young advisors.

\section{Discussion}

While the evidence base for public involvement has expanded over the past decade, the quality of reporting is often inconsistent, which limits understanding of how it works, for whom, and why (Staniszewska et al., 2017). There is a need to collate, understand and disseminate more evidence on the nature, extent and impact of young people's involvement in research (Brady and Preston, 2017). The Y-SBNT study sought to explore ways in which young people with experience of using substance misuse services could be involved in all aspects of a study of this nature. It provided an opportunity to reflect on how the rhetoric of involvement was operationalised in reality, and to reflect on the learning that emerged from this process.

The Y-SBNT study, as with many studies involving young people in health research, began with an adult-led set up in which plans for involvement were established before young people became involved, rather than collaboratively exploring with young people what would work best for them. In this case, the time taken to establish a group of young advisors and the lack of established YPAG members with relevant experience meant it was difficult to involve young people in the initial stages of the project. If the primary purpose of young people's involvement in research is for them to comment on how to make research materials more "young people-friendly", this is nearer to consultation than authentic participation (Cockburn, 2005), co-production or emancipatory models of involvement (Beresford, 2013; Gibson et al., 2012). The dominant discourses and cultures of health services and research often do not sit easily with partnership initiatives with young people (Todd, 2012). Although consultation can be helpful, it can also be an easy way for researchers to "tick the public involvement box" and could also exclude those young people who are less frequently heard, such as those with experience of alcohol and/or drug problems

\section{Box 2: A new model of involvement when working with young people}

Hub and spoke model with a core ongoing group of young advisors, who might change over time, alongside one-to-one and small group work and one-off consultations. Working in partnership with services, who would recruit and provide ongoing support to young people. Involve young people in recruitment for public involvement, both initially during visits to services and through "snowballing" through young people recruited as advisors. Establish a group of young advisors before a project started, so that young people are able to be involved in the development of the proposal and support the recruitment of a new group of young advisors. Provide opportunities for young people would be involved at all stages of the research, but recognise that not everyone will want or be able to do so. Varying levels of involvement, from consultation to co-production, determined by young people's interests and availability as well as the views of researchers. Public involvement lead(s) with relevant expertise supporting all members of the research team to embed public involvement into their work. Linked to wider discussions within the NIHR and elsewhere about making public involvement in research more inclusive, diverse and accessible. 
(Brady, 2017). Furthermore, focussing just on consultation limits the extent to which young people are able to participate more fully as partners in, or coproduce, research.

Y-SBNT young advisors spoke about the benefits of involvement for their wider peer group as well as personal benefits, including being able to use difficult personal experiences to create positive change: but doing so safely, required building trust and being sensitive to individual circumstances. Young people have a right to be involved in matters that affect them, but in exercising that right, they should be able to influence how they participate as well as exercise the right not to be involved. Individuals who may be under significant stress might see limited personal benefit of being involved as a research collaborator (Beresford, 2000). It can be particularly difficult to involve young people in research on sensitive topics, such as those that are private, stressful or "potentially expose stigmatising, or incriminating information" (Lee, 1993). We found that inclusive involvement requires providing opportunities for young people who want to be involved to do so in ways that work for them. But if, when and how they can be involved is ultimately a matter of individual choice. The model which emerged from young people's involvement in the study recognises this and makes a wider contribution by highlighting processes and dynamics relevant to young people's involvement in substance use research, as well as more widely in public involvement in health and social care services and research. We found that involvement needs to be embedded in everyday practices, systems and cultures, but at the same time young people and those facilitating their involvement need to be able to be "critical friends" and to have the independence and resources to be able to drive a more participatory and inclusive involvement. However, this requires careful consideration of the scope and context for the involvement, including the requirements of an RCT by NIHR regulatory and commissioning bodies, available resources and the limits of young people's possible influence (Brady, 2017).

There is currently no systematic way of knowing which young people are involved in research, let alone assessing what form that involvement may have taken or any impacts from involvement (Brady and Preston, 2017). There is also uncertainty about how to increase the diversity of young people involved in health and social care research (Brady, 2015). Therefore, it is important to consider how approaches to involvement and co-production may exclude or include young people in substance use research and more widely, as well as to document that involvement. This paper contributes to this body of knowledge, both through the model which emerged through this process (Box 2) and our reflections on the learning which emerged during this process.

\section{Note}

1. Undertaken at the University of West of England, Bristol, UK as part of a scholarship supported by Professor David Evans and Barry Percy-Smith.

\section{References}

Alderson, P. (2014), "Children as patients", in Melton, G.B., Ben-Arieh, A., Cashmore, J., Goodman, G.S. and Worlet, N.K. (Eds), The Sage Handbook of Child Research, SAGE, London, pp. 100-17.

Beresford, P. (2000), "Service users' knowledges and social work theory: conflict or collaboration?", British Journal of Social Work, Vol. 30 No. 4, pp. 489-503.

Beresford, P. (2013), "From 'other' to involved: user involvement in research: an emerging paradigm”, Nordic Social Work Research, Vol. 3 No. 2, pp. 139-48.

Bird, D., Culley, L. and Lakhanpaul, M. (2013), "Why collaborate with children in health research?: an analysis of the risks and benefits of collaboration with children", Archives of Disease in Childhood: Education and Practice Edition, Vol. 98 No. 2, pp. 42-8.

Brady, L.M. (2015), "Guest blog: involving children and young people in health and social care research: the need for a new perspective", BMJ Archives of Disease in Childhood, 6 January, available at: http://blogs. bmj.com/adc/2015/01/06/guest-blog-involving-children-and-young-people-in-health-and-social-careresearch-the-need-for-a-new-perspective/

Brady, L.-M. (2017), "Rhetoric to reality: an inquiry into embedding young people's participation in health services and research", PhD, University of the West of England, available at: http://eprints.uwe.ac.uk/29885 (accessed 22 February 2018). 
Brady, L.-M. and Preston, J. (2017), "Evaluating the extent and impact of young people's involvement in National Institute for Health Research (NIHR) studies: an assessment of feasibility", Report of a project commissioned by the James Lind Initiative, Oxford, available at: http://generationr.org.uk/? $p=1375$

Brady, L.M., Davey, C., Shaw, C. and Blades, R. (2012), "Involving children and young people in research - principles into practice", in Beresford, P. and Carr, S. (Eds), Social Care, Service Users and User Involvement: Building on Research, Jessica Kingsley, London, pp. 226-42.

Brady, L.-M. and Templeton, L., young co-presenter (2014), "Involving children and young people in research: the usual suspects?", INVOLVE 2014: Changing Landscapes, National Exhibition Centre, NIHR INVOLVE, Birmingham, 26-27 November 2014, available at: www.invo.org.uk/posttypeconference/involving-childrenand-young-people-in-research-the-usual-suspects/

Brady, L.-M. and Templeton, L., young co-authors (2015), "Involving children and young people in research: not the usual suspects", INVOLVE Newsletter, pp. 1-2, available at: www.invo.org.uk/posttypenewsletter/ winter-2014-15/

Braun, V. and Clarke, V. (2013), Successful Qualitative Research: A Practical Guide for Beginners, SAGE, London.

Brett, J., Staniszewska, S., Mockford, C., Herron-Marx, S., Hughes, J., Tysall, C. and Suleman, R. (2014), "Mapping the impact of patient and public involvement on health and social care research: a systematic review", Health Expectations, Vol. 17 No. 5, pp. 637-50.

Cockburn, T. (2005), "Children's participation in social policy: inclusion, chimera or authenticity?", Social Policy and Society, Vol. 4 No. 2, pp. 109-19.

Copello, A., Orford, J., Hodgson, R. and Tober, G. (2009), Social Behaviour and Network Therapy for Alcohol Problems, Routledge, London.

Cree, V.E., Kay, H. and Tisdall, K. (2002), "Research with children: sharing the dilemmas", Child and Family Social Work, Vol. 7 No. 1, pp. 47-56.

Department of Health (2013), "Chief medical officer's annual report 2012: our children deserve better: prevention pays", London, available at: www.gov.uk/government/publications/chief-medical-officers-annualreport-2012-our-children-deserve-better-prevention-pays (accessed 22 February 2018).

Eisenhardt, K.M. (1989), "Building theories from case study research", Academy of Management Review, Vol. 4 No. 14 , pp. 532-50.

Evans, D., Coad, J., Cottrell, K., Dalrymple, J., Davies, R., Donald, C., Laterza, V., Long, A., Longley, A., Moule, P., Pollard, K., Powell, J., Puddicombe, A.R., Rice, C. and Sayers, R. (2014), "Public involvement in research: assessing impact through a realist evaluation", Health Services and Delivery Research, Vol. 2 No. 36, pp. 1-128.

Filipe, A., Renedo, A. and Marston, C. (2017), "The co-production of what? Knowledge, values, and social relations in health care", PLOS Biology, Vol. 15 No. 5, p. e2001403, available at: https://doi.org/10.1371/ journal.pbio.2001403

Fleming, J. and Boeck, T. (Eds), (2012), Involving Children and Young People in Health and Social Care Research, Routledge, London.

Franklin, A. and Sloper, P. (2005), "Listening and responding? Children's participation in health care within England", International Journal of Children's Rights, Vol. 13, pp. 11-29.

Gibson, A., Britten, N. and Lynch, J. (2012), "Theoretical directions for an emancipatory concept of patient and public involvement”, Health, Vol. 16 No. 5, pp. 531-47.

Hood, S., Kelley, P. and Berry, M. (1996), "Children as research subjects: a risky enterprise", Children and Society, Vol. 10 No. 2, pp. 117-28.

INVOLVE (2015), "Involving children and young people", INVOLVE, available at: www.invo.org.uk/find-outmore/how-to-involve-people/involving-children-and-young-people/ (accessed 22 February 2018).

INVOLVE (2016), "What is public involvement in research?", INVOLVE, available at: www.invo.org.uk/find-outmore/what-is-public-involvement-in-research-2/ (accessed 22 February 2018).

Kirby, P. (2004), A Guide to Actively Involving Young People in Research: For Researchers, Research Commissioners, and Managers, NIHR INVOLVE, Southampton. 
Lave, J. and Wenger, E. (1991), Situated Learning: Legitimate Peripheral Participation, Cambridge University Press, Cambridge.

Lee, R.M. (1993), Doing Research on Sensitive Topics, Sage Publications, London.

Mawn, L., Welsh, P., Stain, H.J. and Windebank, P. (2015), "Youth speak : increasing engagement of young people in mental health research", Journal of Mental Health, Vol. 24 No. 5, pp. 271-5.

Powell, M.A. and Smith, A.B. (2009), "Children's participation rights in research”, Childhood, Vol. 16, pp. 124-42.

Richards, S., Clark, J. and Boggis, A. (2015), Ethical Research with Children: Untold Narratives and Taboos, Palgrave Macmillan, Basingstoke.

Shaw, C., Brady, L.M. and Davey, C. (2011), Guidelines for Research with Children and Young People, National Children's Bureau, London, available at: www.participationworks.org.uk/resources/guidelines-forresearch-with-children-and-young-people

Staley, K. (2009), Exploring Impact: Public Involvement in NHS, Public Health and Social Care Research, NIHR INVOLVE, Southampton, available at: www.invo.org.uk/posttypepublication/exploring-impact-publicinvolvement-in-nhs-public-health-and-social-care-research/

Staniszewska, S., Brett, J., Simera, I., Seers, K., Mockford, C., Goodlad, S., Altman, D.G., Moher, D., Barber, R., Denegri, S., Entwistle, A., Littlejohns, P., Morris, C., Suleman, R., Thomas, V. and Tysall, C. (2017), "GRIPP2 reporting checklists: tools to improve reporting of patient and public involvement in research", Research Involvement and Engagement, Vol. 3 No. 13, available at: https://researchinvolvement.biomedcentral. com/articles/10.1186/s40900-017-0062-2

Todd, L. (2012), "Critical dialogue, critical methodology: bridging the research gap to young people's participation in evaluating children's services”, Children's Geographies, Vol. 10 No. 2, pp. 187-200.

United Nations (1989), "Convention on the rights of the child", Office of the United Nations High Commissioner for Human Rights, Geneva, available at: www.ohchr.org/EN/Professionallnterest/Pages/CRC.aspx (accessed 22 February 2018).

Velleman, R.D., Templeton, L.J. and Copello, A.G. (2005), "The role of the family in preventing and intervening with substance use and misuse: a comprehensive review of family interventions, with a focus on young people", Drug and Alcohol Review, Vol. 16 No. 24, pp. 93-109.

Waldman, J. (2005), "From rhetoric to reality: the involvement of children and young people with mental ill health in research", in Lowes, L. and Hulatt, I. (Eds), Involving Service Users in Health and Social Care Research, Routledge, London, pp. 152-62.

Watson, J., Back, D., Toner, P., Lloyd, C., Day, E., Brady, L.M., Templeton, L., Ambegaokar, S., Parrott, S., Torgerson, D., Cocks, K., Gilvarry, E., McArdle, P. and Copello, A. (2015), "A randomised controlled feasibility trial of family and social network intervention for young people who misuse alcohol and drugs: study protocol (Y-SBNT)", Pilot and Feasibility Studies, Vol. 1 No. 8, available at: https://pilotfeasibilitystudies.biomedcentral. com/articles/10.1186/s40814-015-0004-4

Watson, J., Toner, P., Day, E., Back, D., Brady, L.M., Fairhurst, C., Renwick, C., Templeton, L., Akhtar, S., Lloyd, C., Li, J., Cocks, K., Ambegaokar, S., Parrott, S., McArdle, P., Gilvarry, E. and Copello, A. (2017), "Youth social behaviour and network therapy (Y-SBNT): adaptation of a family and social network intervention for young people who misuse alcohol and drugs a randomised controlled feasibility trial", Health Technology Assessment, Vol. 21 No. 15, available at: www.journalslibrary.nihr.ac.uk/hta/hta21150/\#/abstract

Wenger, E. (1998), Communities of Practice: Learning, Meaning and Identity, Cambridge University Press, Cambridge, MA.

\section{Further reading}

Heron, J. and Reason, P. (1997), "A participatory inquiry paradigm”, Qualitative Inquiry, Vol. 3 No. 3, pp. 274-94.

Moules, T. (2005), "Research with children who use NHS services: sharing the experience", in Lowes, L. and Hulatt, I. (Eds), Involving Service Users in Health and Social Care Research, Routledge, London, pp. 140-51.

Sinclair, R. (2004), "Participation in practice: making it meaningful, effective and sustainable", Children and Society, Vol. 18 No. 2, pp. 106-18. 


\section{Authors affiliations}

Louca-Mai Brady is an Independent Research Consultant based in London, UK; and is at the Department of Health and Social Sciences, University of the West of England, Bristol, UK.

Lorna Templeton is an Independent Research Consultant based in Bristol, UK.

Paul Toner is based at the Department of Health Sciences, University of York, York, UK.

Judith Watson is a Senior Research Fellow at the York Trials Unit, Department of Health Sciences, University of York, York, UK.

David Evans is a Professor in Health Services Research at the Department of Health and Social Sciences, University of the West of England, Bristol, UK.

Barry Percy-Smith is based at the Centre for Applied Childhood Youth and Family Research, University of Huddersfield, Huddersfield, UK.

Alex Copello is a Professor at the School of Psychology, University of Birmingham, Birmingham, UK; and is at Birmingham and Solihull Mental Health Foundation Trust, Birmingham, UK.

\section{About the authors}

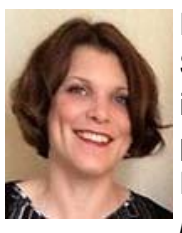

Louca-Mai Brady is a Research Consultant and a Research Associate at Kingston and St George's Joint Faculty of Health, Social Care and Education. She has longstanding interests in children and young people's involvement in health and social care research, policy and practice. Her contribution to this journal was informed by her recent Doctoral Research at the University of the West of England on "Embedding Young People's Participation in Health Services and Research". Previous roles include Senior Research Officer at the National Children's Bureau Research Centre, where she led work on the involvement in children and young people in research, and Principal Research Adviser at Turning Point. Louca-Mai Brady is the corresponding author and can be contacted at: loucamai.brady@gmail.com

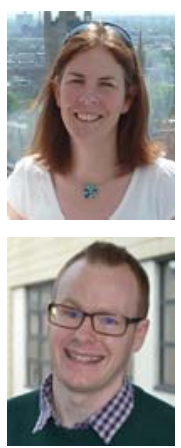

Lorna Templeton is an Independent Research Consultant with over 20 years of experience of conducting UK and international research in to how addiction affects families, including when someone is bereaved through substance use. Lorna has published articles widely and is a Trustee of Adfam and AFINet.

Dr Paul Toner is a Chartered Psychologist and Associate Fellow of the British Psychological Society. He is currently a Society for the Study of Addiction (SSA) Griffith Edwards Academic Fellow based in the Department of Health Sciences at the University of York, developing alcohol screening and assessment measures for young people. Paul is committed to a career in addiction research and has a particular interest in researching alcohol-related risk and harms at individual, family, community and population levels.

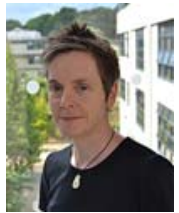

Dr Judith Watson is a Senior Research Fellow at the University of York. Her research interests are in recruitment to randomised controlled trials; trial design issues; podiatric research; addiction and mental health research. Judith has more than 15 years of experience of coordinating and managing large scale randomised controlled trials in both primary and secondary care across the musculoskeletal, wound care and addiction fields. As well as being involved in the day-to-day realities of running trials, she has experience of many trial aspects, including recruitment, methodological issues and design.

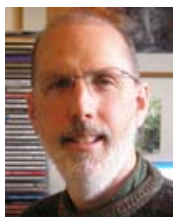

David Evans is a Professor in Health Services Research, University of the West of England with a strong focus on patient and public involvement. He initiated People in Health West of England, a collaborative initiative on public involvement in research with the National Institute for Health Research (NIHR) Collaboration for Leadership in Applied Health Research and Care (CLAHRC West), the West of England Academic Health Science Network, the Clinical Research Network West of England and Bristol Health Partners (http://www.phwe.org.uk/). He was the Principal Investigator on a study on public involvement in research for the NIHR Health Services \& Delivery Research programme. 
Barry Percy-Smith is a Professor of Childhood Youth and Participatory Practice at the University of Huddersfield, UK. He has extensive experience as an Action Researcher in Research, Evaluation and Development projects with children, young people and practitioners in a wide range of public sector contexts. His main interests are in children and young people as active agents of change and participatory approaches to learning and change in organisations and communities. He has undertaken numerous projects concerning the theory and practice of child and youth participation and youth transitions and has published widely on these issues including A Handbook of Children and Young People's Participation: Perspectives from Theory and Practice (co-edited with Nigel Thomas, Routledge, 2010).

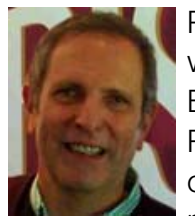

Professor Alex Copello has a BSc, an MSc, and a PhD Degree and is currently working as an Associate Research Director and Consultant Clinical Psychologist at Birmingham and Solihull NHS Foundation Trust and a Professor of Addiction Research at the School of Psychology, the University of Birmingham. His career combines clinical and academic work. Using both qualitative and quantitative methods his interests include the study of psychosocial approaches to addiction, the impact of addiction upon families and friends and the development and evaluation of family and social network based psychological interventions for addiction and mental health problems. Alex has received NIHR and MRC research funding over the past few years and publishes regularly and widely in international academic scientific journals.

For instructions on how to order reprints of this article, please visit our website: www.emeraldgrouppublishing.com/licensing/reprints.htm

Or contact us for further details: permissions@emeraldinsight.com 